\title{
Library value and impact: taking the step from knowing it to showing it
}

\author{
Mary Dunne, Mairea Nelson, Lucy Dillon and Brian Galvin
}

\begin{abstract}
The National Documentation Centre on Drug Use (NDC) is a unique Irish information resource that embraces elements of several library types: national, public, special, academic, digital, and health. This paper presents the results of an evaluation study carried out by NDC staff in two parts, a value survey and impact interviews. Both quantitative and qualitative methods were used to examine aspects of the value and impact of the NDC's resources and services. Many elements of our approach worked well and contributed to the achievement of our aims and objectives. We outline our approach and suggest some modifications that we might make if we were to repeat the study.
\end{abstract}

\section{Introduction}

Demonstrating library value and impact is difficult (Jubb, Rowlands and Nicholas, 2013; Lacey Bryant and Gray 2006). Yet library management requires us to ask ourselves: Are we meeting our clients' needs and our organization's goals effectively, and what is the impact of our efforts? (O'Connor, 2002).

\section{Authors}

Mary Dunne is an Information Officer in the National Documentation Centre on Drug Use, based in the Health Research Board, Dublin. Her qualifications include a Masters in Psychology and a Masters in Information and Library Studies (Distinction).

Email: mdunne@hrb.ie

Mairea Nelson is an Information Officer in the National Documentation Centre on Drug Use at the Health Research Board. She has a Masters in Applied Social Research from Trinity College Dublin.

Lucy Dillon is a freelance social researcher with over 15 years of experience in social research and evaluation. She has carried out research on a wide range of topics while employed by a variety of organisations in Ireland and the UK.

Brian Galvin MA, MLIS is Senior Information Specialist in the National Documentation Centre on Drug Use at the Health Research Board. He currently chairs IFLA's Health and Biosciences section. 
The National Documentation Centre on Drug Use (NDC) is an information resource that supports researchers, policy makers, educators and practitioners working to develop the knowledge base around drug and alcohol use. The NDC is based within the Health Research Board, which is the lead agency in Ireland supporting and funding health research.

Marking ten years of service in 2012, NDC staff carried out an evaluation study in two parts. The first examined aspects of value (users' satisfaction with, and the usefulness of, NDC resources and services), and the second investigated impact (how using the NDC affected users' work and study). This paper presents our approach, our key findings, and the lessons we learned along the way.

\section{$1.1 \quad$ Objectives}

Our study aim was to provide a picture of NDC value and impact that could inform future service development.

The primary objectives of the study were to assess:

- users' satisfaction with NDC services;

- the usefulness of NDC resources for users' work and study;

- the impact of the NDC on users' work and study.

\subsection{Setting}

The NDC electronic repository, available through our website, provides access to a comprehensive collection of Irish and international research and information related to alcohol and other drugs. This resource is supplemented by our public library of hardcopy books and reports, journals and bibliographic databases.

The NDC embraces elements of several library types: national, public, special, academic, digital, and health. This broad remit calls for particular care in the choice of assessment tools and in making comparisons with other library studies. Health, special, and academic libraries, for example, normally have a defined population and setting (such as students in a university, employees of an organisation, or medical staff in a hospital). In contrast, the NDC is used by practitioners, policy makers and students of health, social care, criminal justice and related fields, across Ireland and beyond.

\section{Literature review}

\subsection{Defining terms}

The terminology of library evaluation is complex; the terms value and impact have been variously defined in the literature over the years. Although a thing can have value but no impact (and vice versa), the two terms are related (Cram, 1999). Impact is often described as the effect of a service on its users (and others) (Lockyer, Conyers and Creaser, 2006; Markless and Streatfield, 2006; Poll and Payne, 2006). Urquhart and Hepworth $(1995,33)$ define value as "the benefit the user obtains from the use of information and the effect of that use". In this sense, impact may be viewed as an aspect of value. 
Impact may also be viewed as related to outcome, with some authors treating the terms as inter-changeable (McNicol, 2005), while others provide distinct, sometimes contrasting, definitions (South Australian Community Health Research Unit, 2008; Bawden et al., 2009; Folio, 2009; Lockyer, Conyers and Creaser, 2006; Abels, Cogdill and Zach, 2004). Perhaps the most straightforward distinction between outcome and impact is made by Brettle et al. $(2011,20)$ :

"Outcome measures are used to determine the effectiveness of an intervention (whether the intervention works), whereas impact measures seek to establish whether the intervention has made a difference."

(Brettle et al., 2011, 20)

Poll (2012a) shows how both impact and outcome contribute to value.

An assessment of impact therefore determines what real difference a library or information service (LIS) is making to its users, usually in terms of effects on their work (Bawden et al., 2009). These effects, or changes, may be immediate or long-term, intended or unintended, positive or negative (Poll, 2005; Poll and Payne, 2006). Markless and Streatfield $(2006,64)$ identified four types of change that can occur for users as a result of their contact with a library's resources:

- affective - effects on attitudes or perceptions (e.g. increased levels of confidence);

- knowledge-based - knowing about key sources of relevant information (e.g. what database is most appropriate);

- behavioural - people do things differently (e.g. doing something more or less often);

- competence-based - people do things more effectively (e.g. improved search techniques).

\subsection{Measuring value and impact}

The literature in this area suggests that there are two main purposes for undertaking an impact study. The first is to demonstrate value. The second is to better understand LIS users, and in so doing to provide them with a better service (Botha, Erasmus and Van Deventer, 2009). It is therefore not surprising that most impact studies incorporate, or are done in conjunction with, measurements of satisfaction with and usefulness of services (Powelson and Reaume, 2012; Urquhart et al., 2010; Bawden et al., 2009; Dunn et al., 2009).

Selection of the study population requires careful consideration. Direct library users may be easy to identify; however, libraries (even those with a defined population) rarely cater for users of only one type or profession. An impact measurement appropriate for one group of users may not be appropriate for another; for example, in the case of nurses it may be more appropriate to measure the LIS impact on competencies rather than on clinical decision making (O’Connor, 2002).

Direct users are not the only stakeholders impacted by services. Effects may ensue for indirect users (patients, employers, the wider community), and for parent 
organisations (Tanner, 2012; Urquhart and Brettle, 2012; Cram, 1999). In the health area, Abels, Cogdill and Zach (2002) developed a taxonomy which mapped the contributions made by LIS to organisational goals. Elucidating this connection can be a strong demonstration of value (ACRL, 2012; Dalton, 2012; Lacey Bryant and Gray, 2006; Urquhart, 2004).

There are many issues to be considered when commencing an impact study, including timescale, objectives, participants, methods, intended audience and dissemination. The literature, and in particular the bibliography by Poll (2012b), contains a multitude of useful resources and studies written on this topic. Weightman et al. (2009) provide suggestions for a practical, but "low-bias" impact study for health libraries and basic principles of questionnaire and interview surveys. Markless and Streatfield (2005) present 12 laws of impact evaluation and outline stages of the research process. The SCONUL Impact Initiative also proposes stages in assessing the impact of higher education libraries, from choosing an intervention and relevant indicators to presenting results (Payne, 2006).

Other resources include output from library collaborations that have developed toolkits with templates for surveys, case studies and advice for developing impact indicators (LIHNN, 2012; NHS SHALL, 2009; London Health Libraries Network, 2008; Evidence Base research and evaluation services, 2006; SCONUL, n.d). And some authors have published their survey or interview instruments (Bawden et al., 2009; Information Technology Primary Care Research Group, 2009; Weightman et al., 2009; Yeoman et al., 2001).

In academia and in the health sector there are concerted efforts to establish consistency in library practice and research. Universal standards provide clear guidance on best practice. However, these top-down ideals must be appropriate to the realities of librarians in practice (Høivik, 2013); and take into account the needs of unique user populations and institutional environments (ACRL, 2011).

Both the LQAF (library quality assessment framework) for NHS libraries in England (NHS SHALL, 2012), and the ACRL standards (2011) outline what is required of librarians to demonstrate the effectiveness and impact of their libraries. The new international standard, ISO 16439: Methods and procedures for assessing the impact of libraries, has been designed to provide clarity and consistency to all aspects of assessment (Hiller, 2013; Poll, 2013; Poll, 2012a).

"Measurement is the key element in the evaluation process" (Brettle et al., 2011, 19). Yet, despite a wealth of helpful advice from sources within the profession, measuring a library's impact on the user remains challenging. Contributing to this challenge is the fact that people's behaviour can be influenced by any number of factors (Botha, Erasmus and Van Deventer, 2009). It is difficult to isolate cause and effect as they apply to use of a service and subsequent change. Both Brettle et al. (2011) and Cullen (2004) make the case that information provision (the LIS "intervention"), tends to be a more complex input than the defined interventions usually required of randomised controlled trials. LIS impact studies tend to rely on the subjective views of users collected in cross-sectional surveys (Dunn et al., 2009; Abels, Cogdill and Zach, 2002; Yeoman et al., 2001; Cram, 1999). Urquhart $(2004,204)$ advises that, while such surveys may not yield strong 
evidence, they can be useful as long as the researcher accepts their limitations, takes care to reduce bias, and builds in a mechanism to facilitate learning. Similarly, Cram $(1999,8)$ suggests that when measuring value, librarians are "not attempting to establish an objective truth", and that the extra effort required to move from approximately right to exactly right in this situation is a waste of resources.

A number of indicators may be used to provide a measure of LIS value and impact (Tanner, 2012). Economic value may be demonstrated by libraries through cost-benefit analysis of services. Social value is a more nebulous concept that examines aspects of worth for the individual or community. Usefulness of LIS provides an indicator of value to users. And although as a psychological construct user satisfaction has severe limitations, it also may be used as an indicator of social value (Cram, 1999). Matthews (2013) suggests "ease of use, noise reduction, quality, adaptability, time and cost savings" as user criteria indicating value.

Authors of the SCONUL Impact Initiative define an impact indicator as "a piece of information that indicates whether change has occurred" (SCONUL, n.d.), and they provide detailed advice on developing indicators of change that are clear and appropriate. It is difficult to distinguish LIS contributions from other contributions to decision making, and some authors would suggest that specific measures in this area should be excluded from an impact study (Abels, Cogdill and Zach, 2002). However, measures such as time saved, change in activity, or avoidance of undesirable outcomes, can be powerful indicators of impact, and quantitative surveys displaying such impact indicators have been used in numerous studies (Weightman and Williamson, 2005; O’Connor, 2002).

Cullen $(2004,4)$ provides an outline of the theoretical rationale for using both qualitative and quantitative methods to interpret this complex area of cause and effect. She suggests that multiple sources such as observation, transaction log analysis, usage and performance data, and qualitative narratives are "components in a chain of inferences that address impact". This view is in line with the most common mixed methods approach found in the literature (Brettle et al., 2011; Dunn et al., 2009; Weightman et al., 2009; Weightman and Williamson, 2005; Cullen, 2004; Urqhuart, 2004; O'Connor, 2002; Everest and Payne, 2001). In their follow up to the seminal Rochester study, a research project that explored the impact of library services on clinical decision making, Dunn et al. $(2009,310)$ point to the value in the "weaving together of different data gathering techniques" through triangulation of methods.

Online surveys are now being used as an efficient way of collecting data (Health Libraries Inc. and Australian Library and Information Association, 2012).

Dalton's (2012) research on hospital library outcome-based metrics involved a single-question survey: "How did the information provided by the Library help?" There were six pre-defined response options (including "no effect/impact"). Dalton included a link to the survey with replies to any clinical information or reference queries of substance received by the library. Other surveys have been designed to launch automatically following use of a library resource. For instance, the impact assessment method (IAM) devised by Pluye et al. (2005) is a cognitive 
impact assessment tool for electronic information and knowledge resources. This automated questionnaire investigates impact in terms of behaviours (associated with information hits) and attitudes (feelings about information hits). Responses are measured on a five-point impact scale: strongly positive, moderately positive, neutral, moderately negative, strongly negative, with associated constructs of change, reinforcement, no impact and dissatisfaction. Including an evaluation questionnaire with replies to queries from users gives the LIS a quick and current response (reducing memory bias); however, not all impact is immediate, and longterm benefits may not be adequately reflected (Botha, Erasmus and Van Deventer, 2009).

Cognitive assessment tools, such as the IAM described above, aim to overcome some of the limitations of quantitative data collection methods that have been faulted for their inability to explore complex human judgement (O'Connor, 2002). Qualitative methods help uncover the root causes of value (Nitecki and Abels, 2011) and draw out narratives that "tell the story" of LIS impact (NHS SHALL, 2009). In order to gain a deeper insight into issues of behaviour, motivation and the passive value (future use) of resources, authors of impact reviews have recommended both quantitative surveys and qualitative interviews (Brettle et al., 2011; Weightman and Williamson, 2005; O'Connor, 2002).

The critical incident technique (CIT), which can be used for surveys or interviews, has been extensively used for impact studies (Brettle et al., 2011; Rodriguez, 2011; Weightman et al., 2009). The CIT requires users to provide details of a recent information need or use. It is a flexible method that can be used on one occasion or delivered regularly over a set time period to the user group (e.g. once a week over a four-week period) (Folio, 2009). While disadvantages, such as memory or social desirability biases, have been acknowledged, CIT is viewed as a valuable, validated tool and has been used in over 700 studies (Lacey Bryant and Gray, 2006).

\section{Methods}

For our study examining NDC value and impact we used both quantitative and qualitative data-collection methods. As did many similar studies, we used a crosssectional approach, which represents a snap-shot of impact and value at one point in time (Medernach and Franko, 2007; Cullen, 2004). Each part of our study examined different (though related) areas: part one, the quantitative survey, focused on user satisfaction and usefulness of services; part two, the qualitative interviews, examined impact. By combining this information in a mixed methods approach we were able to provide a more complete picture of our worth.

\subsection{Value survey methods}

We chose to use an online survey as a quick and cost-effective data-collection method. We could adapt questions to flow so the various user types (those using the NDC for work, research, study or personal interest) answered questions that were appropriate to them.

Following a small pilot project to assess the questionnaire for clarity and ease of completion, we conducted the survey in April / May 2012. As we wanted to 
collect views of registered and non-registered website and service users, we placed a pop-up link to the survey on our website homepage for four weeks. We sent 2,699 email invitations to all registered users and to other users who had contacted the library during 2011.

In line with advice for the improvement of response rates, we assured confidentiality, kept the questionnaire brief and simple to complete, and sent two reminders (Weightman et al., 2009). Other suggestions, such as personalising requests and adding incentives for completion were not acted upon for practical reasons.

We included 14 questions in two sections: use and satisfaction, and participant's profile. The survey was anonymous, but ended with an invitation to the participant to provide an email address if they wanted to take part in a follow-up qualitative study.

\subsection{Impact interview methods}

This part of the study sought respondents' in-depth views on the NDC's services and resources, the perceived impact of use on their work, and barriers to and facilitators of making impact. In order to reduce researcher and social desirability bias, we employed an independent researcher to conduct interviews. She worked closely with us to agree on purpose, definitions and sample selection, and to develop a topic guide for the interviews.

There were 441 responses to the value survey. The final sampling frame of 57 for the impact study consisted of respondents who:

- agreed to take part in a follow up study (103 of the 441);

- used the NDC for their work (rather than for study or personal interest) (71 of the 103);

- were resident in the Republic of Ireland (63 of the 71);

- and were working (i.e. neither a student nor unemployed/jobseeker) (57of the $63)$.

In order to ensure coverage across certain key variables and to allow us to explore the factors, influences and experiences that might affect the attitudes being studied, we chose a purposive approach to sampling. Two primary sampling criteria were used:

- Work type: broken into four groups - Public sector workers and administrators or managers; Drugs workers; Health and allied health workers; and Researchers and teachers or lecturers;

- Frequency of use of site: daily / weekly, monthly, a few times a year.

A matrix (work type $x$ frequency of use) guided sample selection, ensuring diversity. The resulting purposive selection of 26 people was contacted by email and given more detail on the nature of the study and what their participation would involve. After one targeted follow up, 13 people agreed to take part and were subsequently interviewed. 
Telephone interviews, conducted according to a topic guide, took place in July and August 2012. This method ensured we could include users from all over the country with minimal inconvenience and expense. Interviews lasted between 35 and 45 minutes, and were recorded with participants' consent. Data were then analysed using a Framework approach (a content analysis method, developed at the National Centre for Social Research, which involves the systematic analysis of the recordings of the interviews within a thematic matrix). The key topics and issues emerging from the data were identified through familiarisation with the content of each interview. A series of thematic charts was then drawn up and data from each recording were summarised under each topic. These charts formed the basis for a detailed exploration of views and experiences of the service users.

\subsection{Method limitations}

By opting for an online survey we may have discouraged those without easy access to the internet from taking part. However, the NDC is primarily an online resource and it was felt that most users would have regular internet access.

In general, this type of survey does not allow calculation of a meaningful response rate. Although we sent out 2,699 invitation emails and had 441 respondents (424 via the email link and 17 via the website link), our list of users included those who had registered over a ten-year period, for some of whom the NDC is no longer relevant. Frequency of use was evenly distributed among participants; however, it was not possible to identify non-responders and examine how they may differ from responders.

Participants in the qualitative aspect of the study were self-selected. It is probable that those who volunteer to take part in such interviews have a particular interest and experience that is not shared by other potential participants. We attempted to partially address this by further sampling by frequency of use.

As we were most interested in assessing impact on people's work, we excluded those who used our service for study or research only. Filtering the sample meant that comparisons could not be made between the impact of the services on those who use them for work and those who use them for study or research.

\section{Results}

This section begins by presenting the quantitative findings of our survey, followed by the qualitative interview findings. We provide some of the key results which demonstrate the effectiveness of our methods.

\subsection{Value survey results}

Perception of library value and impact may differ depending on a person's previous experience and competencies (Poll 2012a); therefore background information on type and frequency of library use contributes to a better understanding of findings.

A total of 441 people took part in our online survey:

- Over half (54\%) of respondents visit our website at least once a month; 
- Over half (53\%) of respondents currently studying are at postgraduate level;

- The majority (73\%) of respondents use our website for work (Figure 1).

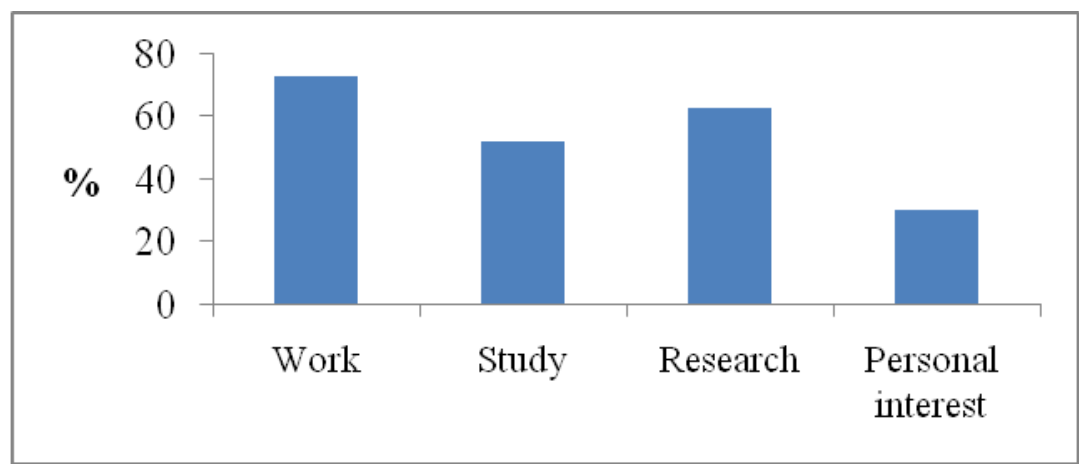

Figure 1: Purposes for which participants use the NDC website.

Note: Participants could choose more than one option.

Usefulness provides an indicator of value and contributes toward a picture of worth. Following the example of other studies, we asked respondents how useful particular resources were to their work or study (Figure 2) (Powelson and Reaume, 2012; Brettle et al., 2011; Dunn et al., 2009).

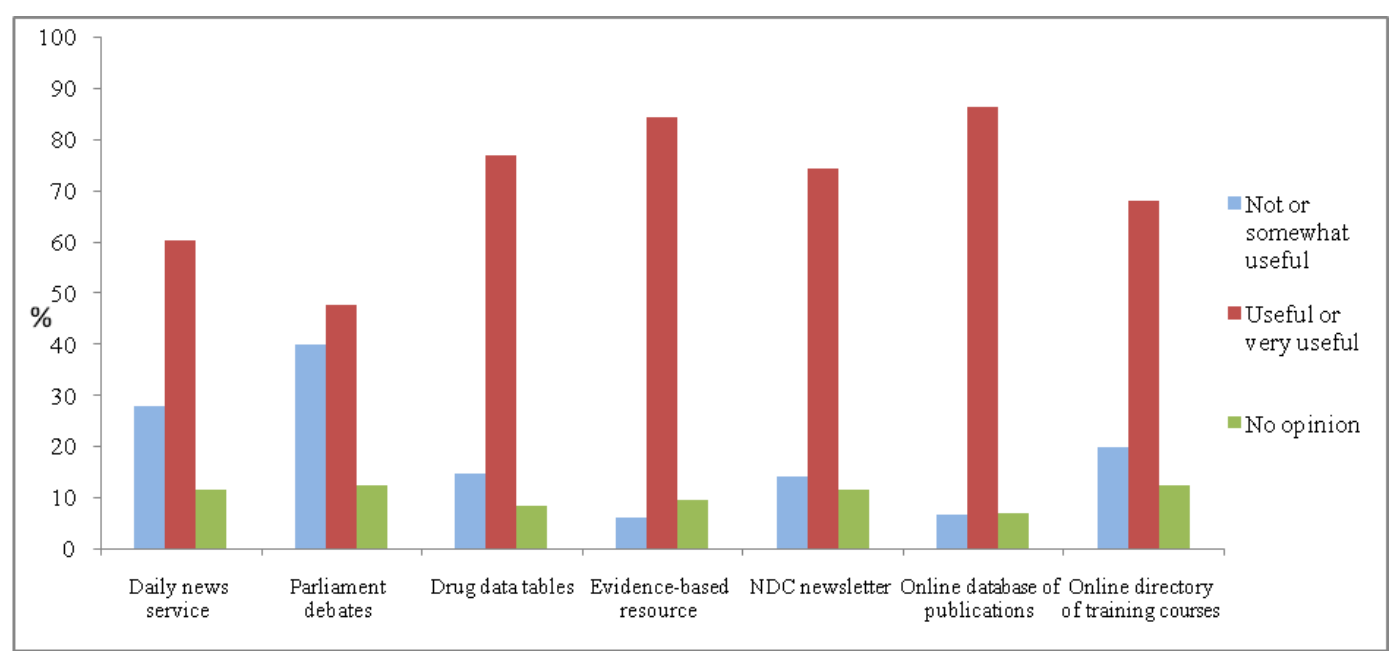

Figure 2: Usefulness of NDC services and resources for participants' work or study.

The survey format enables multi-layered statistical analysis. Using crosstabulations, we were able to see how useful specific resources were by type of user (for example, whether those who use us for work consider a resource more or less useful than those who used us for study, research or personal interest).

Results from our study showed that resources were equally valued by all types of user.

Our second indicator of value was satisfaction with staff and resources.

Satisfaction is "a personally perceived response to an experience" and is generally seen as a measure of quality (Nitecki and Abels, 2011). Poll (2012a), however, 
identifies user satisfaction levels as a measure of service outcome, contributing to a user's perception of library value.

Forty-one per cent (172) of survey respondents said they had contacted the NDC staff with a query. The majority of these $(97 \%)$ were satisfied or very satisfied with the response they received. Forty-eight respondents added comments describing their experience. Staff were described in terms such as "supportive" and "knowledgeable". Twenty-eight respondents included the word "helpful", which indicated that staff expertise provided value.

In the course of the survey, respondents also provided observations related to satisfaction with the NDC website and resources, literature searching, and marketing and promotion, and suggested additions to the library collection. Terms used to describe the NDC included, "crucial", "useful", "excellent", and "very valuable".

\subsection{Impact interview results}

On completion of 13 user interviews, our researcher produced a thorough report of interview results under identified themes. Overall, participants described the NDC's services and resources in very favourable terms. They repeatedly used terms such as "credible", "trusted", "good quality", "time saving" and "up to date". The NDC was described as an integral part of the drug sector, and as having a "natural fit" with it. Participants noted the value for small organisations and services that are often underfunded in having a central resource where all the research is pulled together. They felt that if it were not for the NDC using evidence in their work would be even more difficult.

\subsubsection{Aligning impact measurement with goals}

Taking lessons from other library studies, we reviewed these results in relation to our organisation's goals (Dalton, 2012; Abels, Cogdill and Zach, 2002). Like those of many special libraries with a public service function, the goals of the NDC are driven by strategies other than that of our parent organisation. The National Drugs Strategy, which shapes and defines drugs policy in Ireland, is also a key driver for the NDC. The goals of the NDC are therefore aligned to that of our parent organisation and to those of the National Drugs Strategy (Table 1).

In order to assess the range of impact of the NDC, we divided results into the four impact types described by Markless and Streatfield (2006) and the SCONUL

Impact Initiative: affective, knowledge-based, behavioural, and competence-based change. Each of these impact types denotes a particular type of change which we have aligned with the NDC's strategic goals. In this approach, attainment of goals is measured not only by completion of actions associated with that goal but by the level of change which the service has brought about in those who use it. 


\begin{tabular}{|c|c|c|c|c|}
\hline $\begin{array}{c}\text { Strategic drivers } \\
\text { (organisational } \\
\text { goals) }\end{array}$ & NDC goal & $\begin{array}{c}\text { Logic underpinning } \\
\text { goal }\end{array}$ & Impact type & $\begin{array}{l}\text { Associated } \\
\text { change }\end{array}$ \\
\hline \multirow{3}{*}{$\begin{array}{l}\text { National Drugs } \\
\text { Strategy action: } \\
\text { Disseminate } \\
\text { research findings } \\
\text { and models of best } \\
\text { practice. } \\
\text { Health Research } \\
\text { Board goal 4: } \\
\text { Generate and } \\
\text { synthesise evidence, } \\
\text { and promote the } \\
\text { application of } \\
\text { knowledge to } \\
\text { support decision- } \\
\text { making by } \\
\text { policymakers and } \\
\text { relevant } \\
\text { practitioners. }\end{array}$} & $\begin{array}{l}\text { 1. To be known } \\
\text { as a reliable } \\
\text { source of } \\
\text { information on } \\
\text { all aspects of the } \\
\text { substance use } \\
\text { situation in } \\
\text { Ireland. }\end{array}$ & $\begin{array}{l}\text { Providing a } \\
\text { comprehensive and } \\
\text { reliable resource will } \\
\text { increase confidence } \\
\text { and change attitudes } \\
\text { to research evidence. }\end{array}$ & $\begin{array}{l}\text { Affective } \\
\text { change }\end{array}$ & $\begin{array}{l}\text { Change in } \\
\text { attitudes, } \\
\text { perceptions or } \\
\text { confidence. }\end{array}$ \\
\hline & $\begin{array}{l}\text { 2. To deliver } \\
\text { high quality } \\
\text { information } \\
\text { services and } \\
\text { develop } \\
\text { innovative and } \\
\text { responsive } \\
\text { knowledge } \\
\text { resources. }\end{array}$ & $\begin{array}{l}\text { Providing easy } \\
\text { access to material } \\
\text { through specific, } \\
\text { tailor-made } \\
\text { resources and a } \\
\text { responsive query } \\
\text { service will improve } \\
\text { (impact on) } \\
\text { knowledge } \\
\text { acquisition. }\end{array}$ & $\begin{array}{l}\text { Knowledge- } \\
\text { based change }\end{array}$ & $\begin{array}{l}\text { Know more } \\
\text { about a subject } \\
\text { and its key } \\
\text { sources. }\end{array}$ \\
\hline & $\begin{array}{l}\text { 3. To contribute } \\
\text { to the shift } \\
\text { towards } \\
\text { research-based } \\
\text { approaches to } \\
\text { work and } \\
\text { decision-making } \\
\text { in substance use } \\
\text { work. }\end{array}$ & $\begin{array}{l}\text { Actively increasing } \\
\text { levels of research } \\
\text { literacy and } \\
\text { promoting research } \\
\text { translation into } \\
\text { practice will assist } \\
\text { people to change } \\
\text { behaviour and } \\
\text { develop the } \\
\text { competencies } \\
\text { required to enable } \\
\text { evidence-based } \\
\text { practice. }\end{array}$ & $\begin{array}{l}\text { Competence- } \\
\text { based change }\end{array}$ & $\begin{array}{l}\text { Become more } \\
\text { inquisitive, } \\
\text { critical, } \\
\text { broader } \\
\text { perspective on } \\
\text { issues. } \\
\text { Better able to } \\
\text { find evidence / } \\
\text { do things more } \\
\text { effectively. }\end{array}$ \\
\hline
\end{tabular}

\section{Table 1: Aligning library impact with strategic goals.}

\subsubsection{Interview responses}

The impact study was exploratory and the researcher identified a number of key topics through a systematic analysis of the data gathered through the interviews. These topics were used as headings to group the findings of the impact study and present them in the final report. The headings used were: better informed workers in the drugs sector; better informed policy, programme and project development; better informed interventions with service users; improved course educational development; and better informed written outputs.

We have selected a small sample of the study's findings to illustrate changes under each of the impact types in the schema in Table 1. 


\section{Affective change}

The NDC site was perceived to contain credible evidence of a high quality. Participants felt that they could rely on the research on the NDC site being of "a certain quality". It was described as a "central area for accumulating a whole body of work that is essential to the addiction field" and a "one stop shop" for research.

A recurring theme was that participants had used the services and resources to increase their drug-related knowledge and that it helped keep them "up to date" with what was happening across the sector. This in turn helped them feel more confident in their work. For example, a project worker felt "more credible" in his service delivery as a result, and a staff nurse that "staying connected" through the NDC made her "more confident and competent" in doing her job.

The guidance given by NDC staff was identified as an important element of the service. Participants described how NDC staff had helped them trawl through the data, and had shared their expertise to help them refine their thoughts and build their confidence in accessing evidence.

\section{Knowledge-based change}

The expertise and insight of NDC staff were particularly valued. Their skills were described as "quality, cutting edge, they know what they're about". Participants who contacted the library with a broad request for information on a particular topic were guided by staff to target and refine their search. Staff "took the time to root it out for you" and service users had the opportunity to "draw on their expertise".

Participants described how they were able to find "facts" about drug use on the NDC website for use with clients in one-to-one or group sessions. One project coordinator accessed information on the website to formulate a project plan. He and his colleagues felt they were much better informed and were no longer "winging it" when dealing with their client group.

Some participants used the NDC to access evidence to inform debate and support decision-making arising from a meeting or a discussion with colleagues.

\section{Behavioural change}

Information accessed through the NDC was used by participants to bring about a shift in local policy. For example, a participant had used the NDC to inform a study she had carried out on polydrug use. In response to her paper, her organisation was planning to develop alternative ways to deal with polydrug users locally.

In another example, a staff nurse working in an inpatient rehabilitation service had learned that in order to bring about a change in something at work it was not enough to say "I want to change this", she had to be able to say "We're changing this because research shows...". She had frequently used the NDC to access the information to be able to demonstrate the need for change in this way.

\section{Competence-based change}

A project worker had developed a better understanding of the risks of combining alcohol, opiates and benzodiazepines through reading a number of papers 
accessed through the NDC. He used this insight to inform his initial assessments with service users. He felt he could ask more insightful questions of users and was better equipped to inform them of the risks entailed.

The NDC was described as giving a "window to look in through" on drugs issues for those who are not specialists in the area. For two respondents - a researcher and a social care worker - drugs were only one of a range of areas in which they worked. Both thought the NDC an easy and effective way of getting up to speed with what was happening in the sector when necessary.

\subsubsection{Barriers to and facilitators of impact}

Participants identified areas that could hamper or promote impact. A lack of familiarity with aspects of LIS work was seen as a potential barrier to impact. Unfamiliar terms, such as "new acquisitions" occasionally caused problems and the requirement to comply with copyright restrictions, and the consequent delay in obtaining some research material, were identified as problems by some. A number of participants wanted to see more resources which could be used directly in service delivery.

Participants tended to see the accessibility of NDC resources and the support provided by staff as critical facilitating factors. Some had difficulty in using the website initially but found the support available helped them overcome this and they gradually became more familiar with the site. The information that is made available is very relevant to their work and often "confirmed the consequences of what we're seeing on the ground"; this meant they could use the evidence to support and inform their work.

The environment in which participants work is an important factor in their ability to use the evidence they have found. Most of the participants in our study work in an environment in which evidence is needed to justify decision making, and are supported by their organisation in using the NDC's services and resources. Colleagues are generally open to their use of evidence, which facilitates its impact on their work.

\section{Discussion}

There is a large body of literature on evaluation of library value and impact, but studies vary considerably in scope, definitions, and choice of methods. Perhaps, as Brettle et al. $(2011,18)$ suggest: "There are often too many variables in relation to the models and outcomes being evaluated to create a 'one evaluation model fits all' approach". We therefore chose methods suitable for our particular library.

Many aspects of our approach worked well and contributed to achievement of our aims and objectives. Upon reflection, however, we would make some changes if conducting a similar study in future. We outline our successes and suggest potential modifications below.

By beginning the research process with a quantitative online survey, we were able to assess our value among a wide audience. Measurement of our two value indicators, satisfaction with and usefulness of resources and services, provided us 
with important information about how well we are serving our users and how they view the NDC.

As the aim of our study was to obtain information that could inform future service development, we chose question and answer options with a view to their practical application. We designed our survey so that the responses would provide sufficient detail to modify resources and services if required. We could have broadened the scope of the online survey even further in some cases, for example by asking an additional question of those who indicated that they did not find a resource useful to see if this was due to relevance or delivery issues. Interestingly, our open question asking participants for "any further comments you would like to make about the NDC" yielded some of the strongest examples of our value to users.

Because the NDC has such a varied user population, we did not consider including a question on impact in our survey. However, scales such as that used in the cognitive impact assessment method (Pluye et al., 2005) are applicable to users from any practice setting. The four impact types, affective, knowledgebased, behavioural and competence-based change (Markless and Streatfield, 2006), could also be used to develop answer options. A future survey could therefore include some short impact questions, perhaps using the critical incident technique.

According to the literature, asking participants to base their answers on a specific, recent instance of library use is highly recommended for impact studies and appears to provide a well-structured approach to data collection. However, in our impact evaluation interviews we decided to use the experience of an independent researcher whose interactive probing and questioning methods allowed flexibility in the structure and content of interviews.

We found that this flexible approach to interviews and our broad definition of impact as any change (short- or long-term) that occurred as a result of using the NDC enabled us to deeply explore user views, circumstance and experience without restrictions or presumptions. This gave us a wide scope for our first venture into impact assessment. If designing a study looking at a particular service or resource, however, specific, pre-defined indicators would provide useful guidance for data collection.

Thinking of impact in relation to organisational goals proved a useful exercise. It encouraged us to think in more critical terms about our role in the wider context of our organisation and beyond. By linking our library goals to those of our strategic drivers we can demonstrate how our work is directly contributing to their mission and strategic objectives. For this study we attributed four impact types to our goals. By doing so we could explicitly link impacts to our planned interventions and actions. The impact types were broad and overlapping but served as adequate descriptors to sort results and demonstrate wide-ranging NDCled change.

As Urquhart $(2004,204)$ suggests "An impact study should... provide clues on how service improvements might enhance the impact". We found that an important aspect of our study was assessment of barriers to and facilitators of 
impact. Impact has many determinants. It is important to know not only if we are making a difference but also if there are internal or external impediments involved. Internal issues, such as poor resource design, restricted facilities or access, may need to be addressed to increase impact. External issues, such as lack of organisational support, time or facilities, may also need to be considered. We now know what users find useful, what they think we do well and what we could do better to increase impact. This information will enable us to apply practical steps to service planning.

There are numerous ways of demonstrating library value and impact, and many are yet to be fully explored. Shore (2013) has called for a new way of thinking about, and more useful measures of, value that will capture the benefits accrued through our collaborations, enterprise, and cost-avoidance achievements. At a time when traditional library resources and services face many "competing alternatives" (ACRL, 2010), it is time to fully explore the value and impact of those who work in libraries so that a more complete portrayal of our worth can emerge.

\section{Conclusion}

The NDC evaluation study, using survey and interviews, has provided useful evidence of our value and impact. Based on the views and experiences of respondents, we can say that the NDC's services and resources are valued by our users and have had positive impacts on their work. These impacts have been wideranging and have brought about affective, knowledge-based, behavioural, and competence-based change in practice.

The study provides the NDC with a significant body of evidence on which to base plans for the development of resources and services over the next few years. We have been able to produce a report which documents the value of our services, how they impact on users and contribute to the goals of our strategic drivers. By identifying barriers and facilitators we also have information that will help maximise further utility and impact.

We have learned that there is no one-size-fits-all approach, but that there are numerous tools and resources to help us as librarians demonstrate the importance of our work. Demonstrating value and impact is indeed difficult, but the experience is rewarding. We are confident that what we have learned will be valuable to any library setting out on a similar path.

\section{References}

Abels, E.G., Cogdill, K.W. and Zach, L. (2002) The contributions of library and information services to hospitals and academic health sciences centers: a preliminary taxonomy, Journal of the Medical Library Association, 90(3), 276284. URL: http://www.ncbi.nlm.nih.gov/pmc/articles/PMC116398/ [accessed 25.10.13].

Abels, E.G., Cogdill, K.W. and Zach, L. (2004) Identifying and communicating the contributions of library and information services in hospitals and academic 
health sciences centers, Journal of the Medical Library Association, 92(1), 46-55. URL: http://www.ncbi.nlm.nih.gov/pmc/articles/PMC314102/ [accessed 25.10.13].

ACRL (Association of College and Research Libraries) (2010) Value of academic libraries: a comprehensive research review and report. Researched by Oakleaf, M. Chicago: Association of College and Research Libraries. URL: http://www.ala.org/acrl/sites/ala.org.acrl/files/content/issues/value/val_report.pdf [accessed 17.10.2013].

ACRL (Association of College and Research Libraries) (2011) ACRL standards. URL: http://www.ala.org/acrl/standards/standardslibraries [accessed 15.10.13].

ACRL (Association of College and Research Libraries) (2012) Connect, collaborate, and communicate: a report from the value of academic libraries summits. Prepared by Brown, K and Malenfant, K.J. Chicago: Association of College and Research Libraries. URL: http://www.ala.org/acrl/files/issues/value/val_summit.pdf [accessed 17.10.2013].

Bawden, D., Calvert, A. Robinson, L. Urquhart, C. Bray, C. and Amosford, J. (2009) Understanding our value; assessing the nature of the impact of library services, Library and Information Research, 33(105), 62-89. URL: http://www.lirgjournal.org.uk/lir/ojs/index.php/lir/issue/view/27 [accessed 17.10.13].

Botha, E., Erasmus, R. and Van Deventer, M. (2009) Evaluating the impact of a Special Library and Information Service, Journal of Librarianship and Information Science, 41, 108-123.

Brettle, A., Maden-Jenkins, M., Anderson, L., McNally, R., Pratchett, T., Tancock, J., Thornton, D. and Webb, A. (2011) Evaluating clinical librarian services: a systematic review, Health Information and Libraries Journal, 28, 3-22.

Cram, J. (1999) "Six impossible things before breakfast": a multidimensional approach to measuring the value of libraries. Keynote address in 3rd Northumbria International Conference on Performance Measurement in Libraries and Information Services, Newcastle upon Tyne, 27-31 August, 1999.

Cullen, R. (2004) Evaluating digital libraries in the health sector. Part 2: measuring impacts and outcomes, Health Information and Libraries Journal, 21, 3-13.

Dalton, M. (2012) Key performance indicators in Irish hospital libraries: developing outcome-based metrics to support advocacy and service delivery, Evidence Based Library and Information Practice, 7A. URL: http://ejournals.library.ualberta.ca/index.php/EBLIP/article/view/17442/14526 [accessed 25.10.13].

Dunn, K., Brewer, K., Gard Marshall, J. and Sollenberger, J. (2009) Measuring the value and impact of health sciences libraries: planning an update and replication of the Rochester study, Journal of the Medical Library Association, 97(4): 308-312. URL: http://www.ncbi.nlm.nih.gov/pmc/articles/PMC2759150/ [accessed 22.10.13]. 
Everest, K. and Payne, P. (2001) The impact of libraries on learning, teaching and research. Report of the LIRG seminar held in Leeds, 30 October 2001. Library and Information Research News, 25(81), 18-22. URL:

http://www.lirgjournal.org.uk/lir/ojs/index.php/lir/issue/view/12 [accessed 25.10.13].

Evidence Base research and evaluation services (2006) The evalued toolkit. Birmingham City University. URL: http://www.evalued.bcu.ac.uk/ or http://www.evalued.bcu.ac.uk/evaluating/impact/index.htm [accessed 25.10.13].

Folio (2009) Maximising the impact of your service (Maxim). URL: http://foliomaxim.pbworks.com/w/page/6853635/FrontPage [accessed 25.10.13].

Health Libraries Inc. and Australian Library and Information Association (2012) Questions of life and death: an investigation into the value of health library and information services in Australia. Canberra: Australian Library and Information Association. URL:

http://www.alia.org.au/sites/default/files/documents/advocacy/HLIALIAValuingHealthInformationServicesReport2012v2.pdf [accessed17.10.13].

Hiller, S. (2013) Standards and academic libraries. Presented at the 10th Northumbria International Conference on Performance Measurement in Libraries and Information Services, University of York, 22-25 July, 2013. URL: https://drive.google.com/folderview?id=0B7NjkbIAN36LUHBabFhSZmU5WG8 \&usp=sharing [accessed 15.10.13].

Høivik, T. (2013) Improving practices. Statistical standards in global libraries. Paper presented at: IFLA World Library and Information Congress, Singapore, 17-23 August, 2013. URL: http://library.ifla.org/229/1/177-hoivik-en.pdf [accessed 15.10.13].

Information Technology Primary Care Research Group (2009) The Information Assessment Method (IAM). Montreal: Department of Family Medicine, McGill University. URL: http://www.mcgill.ca/iam/ [accessed 18.10.13].

Jubb, M., Rowlands, I. and Nicholas, J.(2013) Value of libraries: relationships between provision, usage, and research outcomes. Evidence Based Library and Information Practice, 8(2), 139-152. URL:

http://ejournals.library.ualberta.ca/index.php/EBLIP [accessed 14.10.13].

Lacey Bryant, S. and Gray, A. (2006) Demonstrating the positive impact of information support on patient care in primary care: a rapid literature review, Health Information and Libraries Journal, 23, 118-125.

LIHNN (Library and Information Health Network North West) (2012) MAP: making alignment a priority for health libraries: a toolkit to support the planning, modernisation and delivery of health library and information services. URL: http://resources.lihnn.nhs.uk/wiki/MAP.MainPage.ashx [accessed 25.10.13].

Lockyer, S., Conyers, A. and Creaser, C. (2006) Value and Impact Measurement Programme: report for WGPI, SCONUL. URL: http://vamp.diglib.shrivenham.cranfield.ac.uk/project/Phase\%201\%20report.pdf [accessed 25.10.13]. 
London Health Libraries Network (2008) London Links alignment toolkit: library impact case study. URL: http://www.londonlinks.nhs.uk/resources/alignmenttoolkit [accessed 25.10.13].

Markless, S. and Streatfield, D. (2005) Facilitating the impact implementation programme, Library and Information Research, 29(91). URL:

http://www.lirgjournal.org.uk/lir/ojs/index.php/lir/issue/view/24 [accessed 25.10.13].

Markless, S. and Streatfield, D. (2006) Evaluating the impact of your library. London: Facet Publishing.

Matthews, J. (2013) The value \& economic measures of libraries.Presented at the 10th Northumbria International Conference on Performance Measurement in Libraries and Information Services, University of York, 22-25 July, 2013. URL: https://drive.google.com/folderview?id=0B7NjkbIAN36LUHBabFhSZmU5WG8 \&usp=sharing [accessed 15.10.13].

McNicol, S. (2005) Academic libraries: planning, outcomes and communication. Birmingham: Evidence Base research \& evaluation services. URL: http://www.ebase.bcu.ac.uk/docs/Outcomes_project_report.pdf [accessed 22 .10.13]

Medernach, C. and Franko, J. (2007) Assessing the impact of information services in a regionalized health-care organization, Health Information and Libraries Journal, 24(Suppl. 1), 46-56.

NHS SHALL (Strategic Health Authority Library Leads) (2009) Assessing the impact of health libraries: a practical online toolkit. NHS Library Service England. URL:

http://www.libraryservices.nhs.uk/forlibrarystaff/impactassessment/ [accessed 25.10.13].

NHS SHALL (Strategic Health Authority Library Leads) (2012) NHS Library Quality Assurance Framework (LQAF) England, version 2.2, NHS Library Service England. URL: http://www.libraryservices.nhs.uk/forlibrarystaff/lqaf/ [accessed 15.10.13].

Nitecki, D.A. and Abels, E.G. (2012) Exploring the cause and effect of library value, In Hall, I., Thornton, S. and Town, S. (eds.) Proceedings of the $9^{\text {th }}$ Northumbria International Conference on Performance Measurement in Libraries and Information Services: Proving value in challenging times, University of York, 22-26 August 2011, pp. 319-324. URL:

http://www.york.ac.uk/about/departments/support-and-admin/informationdirectorate/events/northumbria-conference/archive/proceedings/ [accessed 15.10.13].

O'Connor, P. (2002) Determining the impact of health library services on patient care: a review of the literature, Health Information and Libraries Journal, 19, 113.

Payne, P. (2006) The LIRG/SCONUL impact initiative: assessing the impact of HE libraries on learning, teaching, and research, Library and Information 
Research, 30(96), 2-12. URL: http://eprints.bbk.ac.uk/447/1/payne3.pdf [accessed 15.10.13].

Pluye, P., Grad, R.M., Stephenson, R. and Dunikowski, L.G. (2005) A new impact assessment method to evaluate knowledge resources, AMIA 2005 Symposium Proceedings, 609-613. URL: http://www.ncbi.nlm.nih.gov/pmc/articles/PMC1560543/ [accessed 15.10.13].

Poll, R. (2005) Measuring the impact of new library services. Presented at World Library and Information Congress: 71th IFLA General Conference and Council "Libraries -A voyage of discovery" 14-18 August 2005, Oslo, Norway. URL: http://archive.ifla.org/IV/ifla71/papers/081e-Poll.pdf [accessed 25.10.13].

Poll, R. (2012a) Can we quantify the library's influence? Creating an ISO standard for impact assessment, Performance Measurement and Metrics, 13(2), 121-130.

Poll, R. (2012b) Bibliography: impact and outcome of libraries, ULB Münster. URL: http://www.ifla.org/files/assets/statistics-andevaluation/publications/Bibliography Impact and Outcome 11 2012.pdf [accessed 25.10.13].

Poll, R. (2013) Library standards: how using them can demonstrate value and impact.Presented at the $10^{\text {th }}$ Northumbria International Conference on Performance Measurement in Libraries and Information Services, University of York, 22-25 July, 2013.URL: https://drive.google.com/folderview?id=0B7NjkbIAN36LUHBabFhSZmU5WG8 \&usp=sharing [accessed 20.10.2013].

Poll, R. and Payne, P. (2006) Impact measures for libraries and information services, Library Hi Tech, 24(4), 547-562.

Powelson, S.E. and Reaume, R.D. (2012) Using the results of a satisfaction survey to demonstrate the impact of a new library service model, Health Information and Libraries Journal, 29(3), 223-232.

Rodriguez, D.A. (2012) The 'understanding library impacts' protocol: demonstrating academic library contributions to student learning outcomes in the age of accountability. In Hall, I., Thornton, S. and Town, S. (eds.)Proceedings of the 9th Northumbria International Conference on Performance Measurement in Libraries and Information Services: Proving value in challenging times, University of York, 22-26 August 2011, pp.355-365. URL: http://www.york.ac.uk/about/departments/support-and-admin/informationdirectorate/events/northumbria-conference/archive/proceedings/ [accessed 15.10.13].

SCONUL (n.d.) Impact Initiative: An Outline in 15 Steps. URL: http://vamp.diglib.shrivenham.cranfield.ac.uk/impact/impact-initiative/doingimpact-evaluation-an-outline/an-outline-in-15-steps-not-yet-published [accessed 25.10.13].

Shore, E. (2013) The role of the library in the transformative higher education environment: or fitting our measures to our goals. Presented at the 10th Northumbria International Conference on Performance Measurement in Libraries 
and Information Services, University of York, 22-25 July, 2013. URL: https://drive.google.com/folderview?id=0B7NjkbIAN36LUHBabFhSZmU5WG8 \&usp $=$ sharing [accessed 15.10.13].

South Australian Community Health Research Unit (2008) Planning and Evaluation Wizard, 'Evaluation Zone' : Developing an evaluation plan, Adelaide: South Australian Community Health Research Unit, Flinders University. URL: http://som.flinders.edu.au/FUSA/SACHRU/PEW/pep_eval_ind_impact.htm [accessed 25.10.13].

Tanner, S. (2012) Measuring the impact of digital resources: the Balanced Value Impact Model. London: King's College London. URL: http://www.kdcs.kcl.ac.uk/fileadmin/documents/pubs/BalancedValueImpactMode 1_SimonTanner_October2012.pdf [accessed 25.10.13].

Urquhart, C. (2004) Special topic: how do I measure the impact of my service? [Guideline] In Booth, A. and Brice, A. (eds.) Evidence based practice for information professionals: a handbook. London: Facet Publishing, 210-222. URL: http://ebliptext.pbworks.com/f/Booth+\%26+Brice+2004+EBP+for+Info+Professi onals+-+A+Handbook.pdf [accessed 15.10.13].

Urquhart, C. and Brettle, A. (2012) Measuring value and impact: from theory to practicalities, presented at CILIP Health Libraries Group conference, Health Libraries under the microscope. Protecting your formula. Glasgow Science Centre, 12-13 July 2012. URL:

http://www.libraryservices.nhs.uk/document_uploads/HEALER/Urquhart_Brettle _Measuring_value impact.pdf [accessed 25.10.13].

Urqhuart, C. and Hepworth, J. (1995) The value to clinical decision making of information supplied. London: British Library Research and Development Department. URL:

http://www.aber.ac.uk/en/media/departmental/dis/research/projectreports/valuereport.pdf [accessed 25.10.13].

Urquhart, C., Thomas, R., Ovens, J., Lucking, W. and Villa, J. (2010) Planning changes to health library services on the basis of impact assessment, Health Information and Libraries Journal, 27, 277-285.

Weightman, A.L. and Williamson, J. (2005) The value and impact of information provided through library services for patient care: a systematic review, Health Information and Libraries Journal, 22, 4-25.

Weightman, A., Urquhart, C., Spink, S. and Thomas, R. (2009) The value and impact of information provided through library services for patient care: developing guidance for best practice, Health Information and Libraries Journal, 26,63-71.

Yeoman, A., Cooper, J., Urquhart, C.and Tyler, A. (2001) The value and impact of virtual outreach information services: report of the VIVOS project. Council for Museums, Archives and Libraries. URL: http://www.aber.co/en/media/departmental/dis/research/projectreports/FinalVIVOS-report-copyright-in-ack.pdf [accessed 25.10.13]. 


\section{Open access and copyright}

Library and Information Research is an open access journal. A freely available copy of this paper may be downloaded from the journal's website: http://www.lirgjournal.org.uk.

Copyright and associated moral rights in works published in Library and Information Research are retained by the author(s) but this paper may be used freely, with proper attribution, in educational and other non-commercial settings. 